\title{
DETERMINATION OF TEMPERATURE CONDITIONS FOR A DESIGN OF ENGINEERING CONSTRUCTIONS DURING A FIRE
}

The problem of an engineering constructions design for effects of fire results from contemporary knowledge and procedures used in technical practice, however, is not limited only to norm recommendations, but looks also for other suitable methods of design. To examine fire endurance of engineering constructions by computation it is necessary to perform the determination of temperature in the area through models for follow-up thermal analysis. This article therefore presents principles of choice of appropriate design fire scenario by determination of the whole conception of safety and then presents a valiant solution of determination of the thermal action though the design fire by the form divergent from norm procedures. In addition, in the text it is alerted to deficiency and limitation in work used norm principles.

Keywords: design, thermal effect, fire scenario, design fire

\section{Introduction}

Every examination of fire protection of buildings requires forming of an expert opinion. This opinion predicts not only possible fire and smoke source and expansion, reaction of installed fire protective equipment but also characteristic behaviour of building constructions during a fire. On this basis rises, considering input data and analytical methods used, fire protective design built by the designer, who, in relation to possible hazards, determines such strategies of fire protection that have risk on commonly acceptable level.

From the view of examination of building constructions fire resistance is for the present typical the "trend" of fire building constructions resistance determination with the usage of the Eurocodes. In terms of fire protection is the most important the CSN EN 19911-2 Eurocode 1: Actions on structures - Part 1-2: General actions - Actions on structures exposed to fire [1].

By designing of building constructions on effects of fire it is also possible to use principles of fire protection engineering. Their application doesn't follow the common procedure of determination of thermal conditions (for example fire curve). In these cases the relevant fire characteristic is determined so that it represents one or more fire scenarios, which may occur by particular building.

The procedures for determination of building constructions fire endurance mentioned above are very close in some details, may concur or eventually be complementary to each other.

\section{Requirements and demonstration of building constructions fire resistance}

Fire resistance of building constructions is collectively expressed ability of constructions to resist the effects of fire. Evaluation of fire resistance consists in proof of given requests fulfilment.

Constructions fire resistance requirement in relation to fire risk of fire compartments is determined according to the code of standards about building fire safety (series CSN 73 08xx) or according to other data (for example according to CSN EN 1991-1-2). The fire resistance is on regular basis determined for standard fire process or probable (parametrical) fire process. To the standard fire process correspond fire resistances determined by calculate fire load or by equivalent period of fire duration. The probable fire process is determined according to the specific conditions of considered part of building or technological object, generally with variant temperature course in burning area from standard fire development. Probable fire development is determined by probable period of fire duration and by probable gases temperature [2] or by temperature analysis of parametrical fire development [2].

Constructions fire resistance is determined (demonstrated) by classification according to results of tests according to appropriate test standards or by standard value (for example based on CSN 73 0821), eventually by evaluation (in cases when all factors affecting the fire resistance can be numerically defined) or it is possible to determine it by test and evaluation (in cases when not all factors affecting the fire resistance can be covered by test or when the results of tests require for particular application farther examination) [2].

\footnotetext{
* Petr Kucera ${ }^{1}$, Jiri Pokorny ${ }^{2}$

${ }^{1}$ VSB - Technical University Ostrava, Ostrava-Vyskovice, Czech Republic, E-mail: petr.kucera@vsb.cz, Homepage: http://homel.vsb.cz/ ${ }^{\sim}$ kuc05

${ }^{2}$ Fire Rescue Service of Moravian-Silesian Region, Ostrava-Zabreh, Czech Republic, Homepage: www.jiripokorny.net
} 


\section{Load of constructions exposed to the fire effects}

By building constructions designing for effects of fire it is necessary to analyze their heat and mechanical load [1].

Procedure of design for fire effects takes into account:

- choice of a particular design fire scenario,

- definition of design fire,

- evaluation of temperature in carrying elements,

- evaluation of mechanical behaviour of construction (of mechanical response).

The procedures of design can be divided into element analysis, construction part analysis and the whole construction analysis.

The heat load of the construction can be determined based on nominal or parametric fire curves or fire models (see Fig. 1).

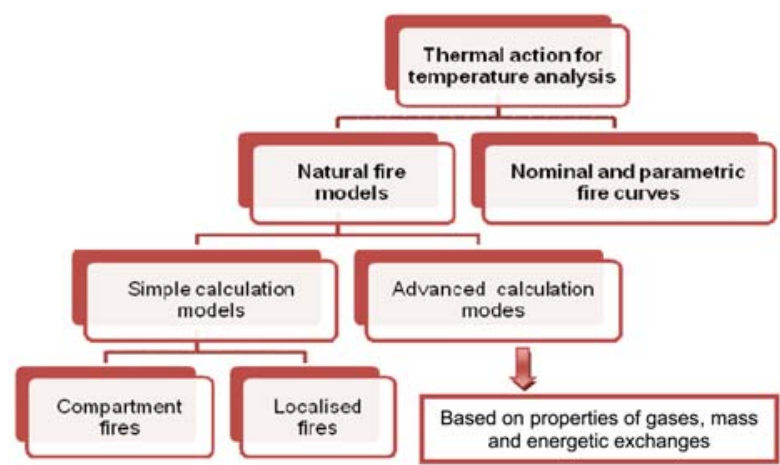

Fig. 1 Thermal action for temperature analysis of the construction (adopted from [1])

Simple fire models are based on specific physical parameters with limited application field. By fires of fire compartment area it is supposed a uniform temperature distribution as function of time by localised fires it is supposed a non-uniform temperature distribution.

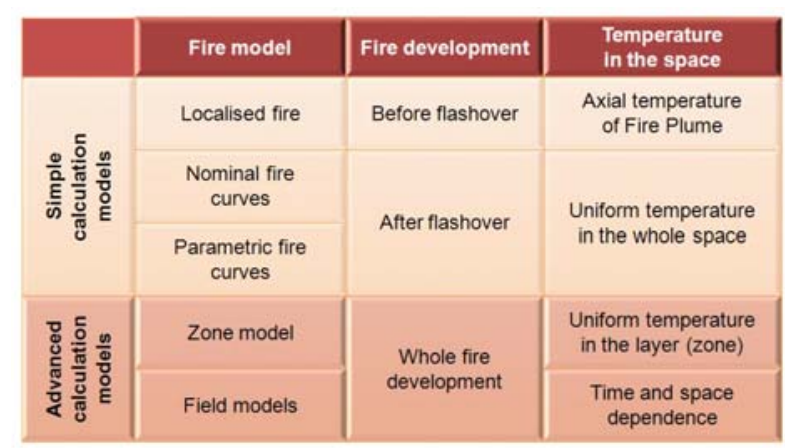

Fig. 2 List of fire models for determination of temperature in the space
Advanced fire models assume using one-zone and two-zone fire models and field models that are based on dynamical fluid and gas models (see Fig.2).

\section{Choice of design fire scenario and design fire}

A choice of fire scenario and design fire is a part of qualitative analysis, which can be called first step in examination of buildings fire safety, when the designer gathers design parameters needed to be able to subsequently examine the fire risk and to determine strategies region for risk maintenance at the acceptable level. Fire scenario describes the development of particular fire in time and space (see Fig. 3). Generally, it is possible to define the fire scenario as a time behaviour description of fire influenced by factors such as environment, human behaviour, fire safety equipment etc.

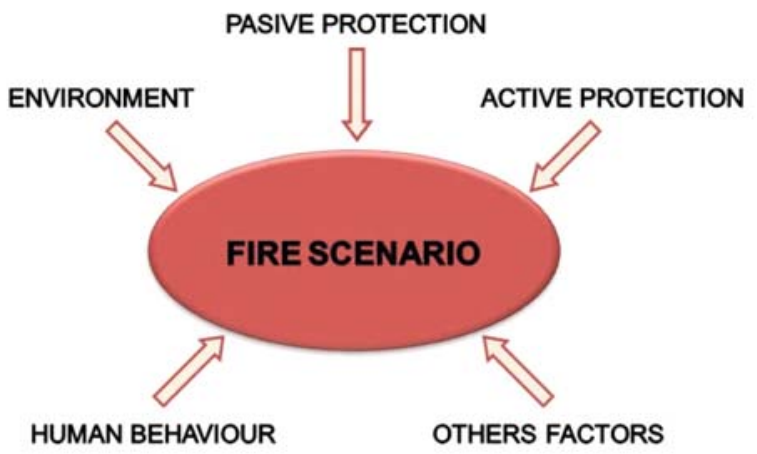

Fig. 3 Fire scenario scheme [9]

In the qualitative analysis it is necessary to choose suitable fire scenarios. Usually are chosen these with less propitious variants of fire development and at the same time with enough high probabilities of their occurrence. At the determination about importance of fire scenarios the high stress lays on expert assessment.

In practice we could determine almost infinite number of possible fire scenarios. But it is impractical and unreal to analyse all the scenarios. In terms of qualitative study it is chosen a final set of so-called design fire scenarios suitable for analysis. Results of these scenarios need to represent an acceptable fire risk upper boundary. In other words these are the most unfavourable fire scenarios with satisfactory occurrence probability with consequences that the society is capable to hold.

Every design fire scenario is represented by a unique appearance of events and is a result of particular set of circumstances associated with fire safety controls

By the selection of design fire scenarios suitable for analysis it is necessary to proceed systematically and to choose such scenarios, in order that at least one of them assess the perspective of material damage risk and other one the perspective of human health and life hazard. As the most suitable way to determine design fire 
scenario is considered the procedure establishing the risk classification, which takes into account consequences and also the probability of fire scenario.

By the risk classification the procedure below can be used:

- selection of possible fire scenarios,

- consideration of scenario appearance probability based on data available and/or on an expert opinion,

- consideration of scenario consequences with using an expert opinion,

- analysis of relative risk of fire scenarios (i.e. product of fire appearance probability and its consequences),

- distribution of fire scenarios by relative risk.

Substeps of procedure for determination of fire scenario risk rating are illustrated in Fig. 4.

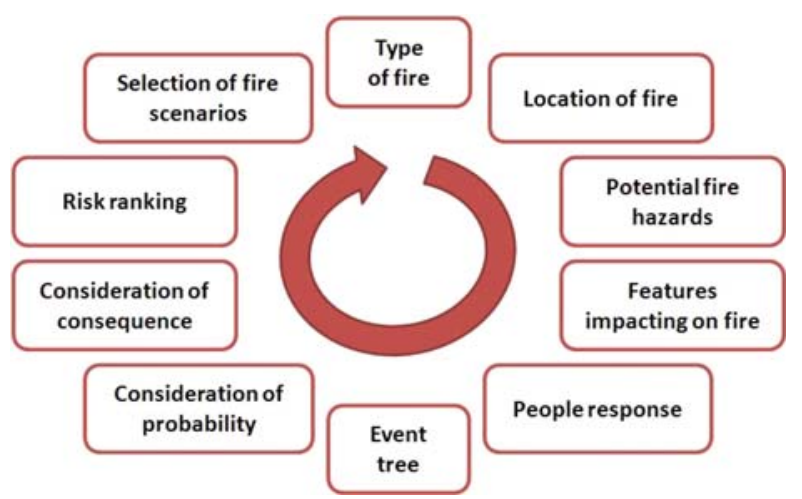

Fig. 4 Fire scenario design scheme (adopted from [10])

Important basis of determination of initial set of possible design fire scenarios are statistical data about fires, their occurrence cause, direct and consequential damages, number of evacuated and saved subjects, number of dead people etc. Data could be used for determination of most probable and also most hazardous fires for a particular (specific) kind of object and character of its usage (purpose).

Usage of event tree and after choice of fire scenarios always depends on an expertise of designer who has to have field experience to be able with certain accuracy to determine probabilities of occurrence of particular phenomena. In particular objects and situations must they, however, decide according to their experience or collective dealing with other experts.

\section{Localised fire}

Localised fire represents the situation when the total ignition of substances is unlikely and a non-uniform temperature distribution in the area is assumed.

Two basic situations are distinguished in term of expansion and spread of flame (see Fig. 5):
- blaze that doesn't affect ceiling; ( $L_{f}<H$, flame length is lower than distance between source of fire and ceiling),

- blaze that affects ceiling; ( $L_{f} \geq H$, flame length is equal or greater than distance between fire source and ceiling). In this case it is necessary to determine horizontal fire length $L_{h}$, which sets out the area of flames radial spread under the ceiling.
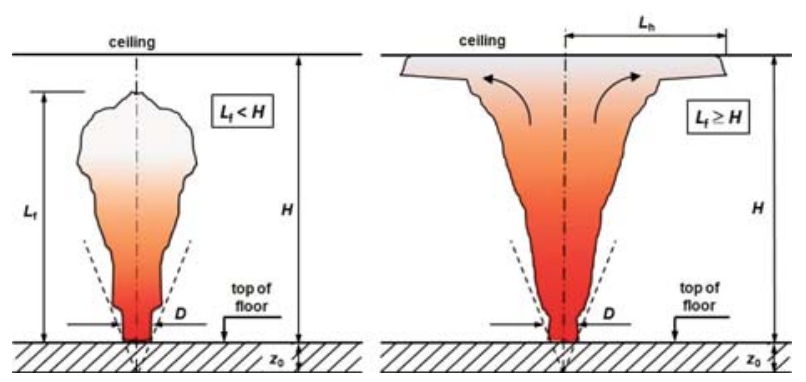

Fig. 5 Spread of flames by the fire in a bounded space [7]

Input data for examination of localised fire effects on engineering structure are flame length $L_{f}$, virtual axis origin $z_{0}$, convective part of heat release velocity $Q_{c}$ and other. Computational process of localised fire expanded in Eurocode 1 is one of the common, but at the same time also simplest, methods for Fire Plume axial temperature determination and for determination of heat flow laid across engineering construction. Modesty of solution is also the reason of significant limit of described method usage. Above all it is about the evaluation limitation considering the height position in space (more precisely in Fire Plume position) and about the accumulative smoke influence.

Relations listed in Eurocode 1 are usable for determination of Fire Plume axial temperature in its final part, thus in smoke zone ${ }^{1}$. Application of calculation methods in other parts of Fire Plume leads to unreal optimistic results [4], [5].

Computing method is, among others, based on presumption that there is a suction of surrounding air with temperature corresponding to the standard conditions of environment (generally $20^{\circ} \mathrm{C}$ ) into the developing combustion gases column. But in real situations during the fires in bounded spaces there is in most cases a creation of smoke layer under ceiling or suspension ceiling construction which goes down. By the Fire Plume passage through the hot gases layer its axial temperature is affected on grounds of ambient conditions changes. In the shape taking Fire Plume there is a suction of gases, whose temperature is higher than the ambient temperature and thereby is the temperature drop with increasing distance above the surface more gradual. Final values of Fire Plume axial temperature without or with consideration of hot gases layer may radically differ and the results obtained by using of Eurocode 1 may be in case of hot gas layer misleading (significantly undersized) [6].

The technique by determination of Fire Plume axial temperature (possible application of localised fire according to the Eurocode 1) is illustrated in Fig. 6. 


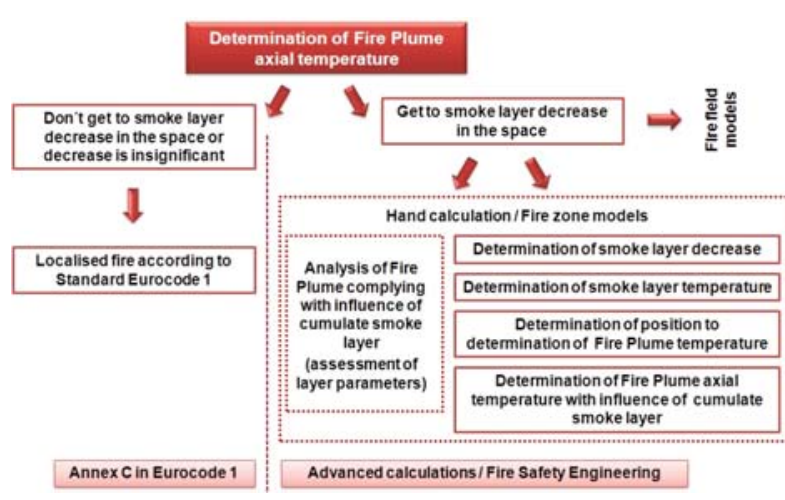

Fig. 6 Technique of determination of Fire Plume axial temperature

The procedure of localised fire according to the standard Eurocode 1 is possible to apply in practice for design of building constructions during the fire conditions without farther related calculation methods rather sporadically. Only by cases of building objects with large geometrical measurements where the smoke layer decrease is very slow and short application period of calculation procedure.

\section{Parametric fire curve}

Flashover may be defined as a transition from localised fire to the combustion of all unprotected flammable gases in the room. The flashover is taken rather as a transition between two states than as a precisely determined event. The initial conditions for flashover appearance are sufficient fuel and sufficient aeration to development of the fire to size needed.

The fire in a bounded space after the flashover (in the phase of fully developed fire) is most frequently described by fire curves with characteristic quick increase of temperature (conventional graphic illustrations of fire intensity). Illustration of afterburning (cooling) by a fire curve is more difficult.

Fire curves of by ventilation controlled fire for different coefficients of ventilation, different thicknesses of fire load and different physical characteristics of constructions bounding fire compartment are generally called parametric fire curves. Equations for determination of parametric fire curves developed from equation of thermal equilibrium. Typical parametric fire curve is divided into two parts (Fig. 7). The first part describes exponential phase of fire development and the second one the linear part of cooling. The line between these phases makes maximum achieved temperature. Maximum achieved temperature information is important for consideration of building construction behaviour during the fire. The course of parametric fire curve is positively affected by fire safety equipment (for example automatic fire extinguishing system).

Parametric fire curve according to the Eurocode 1 (annex A CSN EN 1991-1-2) is valid only for fires with cellulosic type fire load

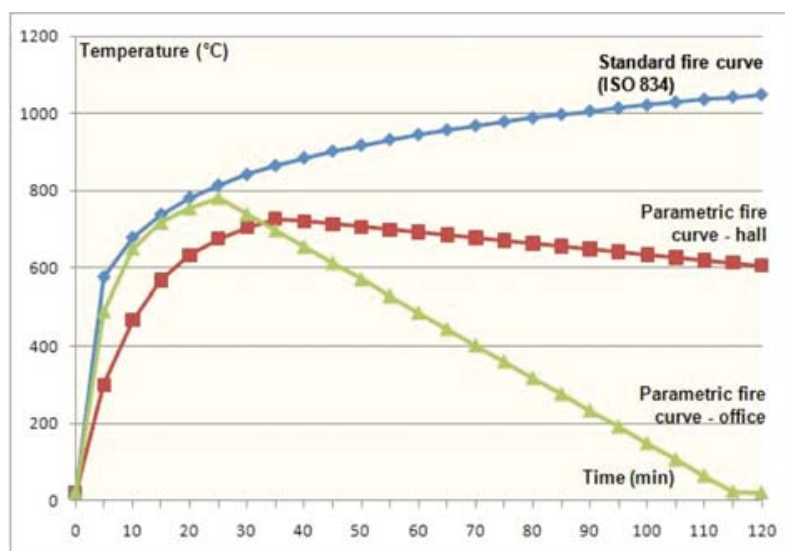

Fig. 7 Parametric fire curves vs. standard fire curve

and for relatively small fire compartments (with size under $500 \mathrm{~m}^{2}$ of floor area with maximum ceiling high $4 \mathrm{~m}$ ). Especially for common hall objects as sales or storage halls this fire curve is unsuitable. It can't be applied by fire compartments with horizontal openings in floor or ceiling (or roof) too.

\section{Fire models}

Most widespread fire models are deterministic models that predict fire development and with it associated processes on the basis of solution of mathematical equations describing physical and chemical processes during the fire. Physical conditions, which determine development and results of fire, are called fire scenarios by these models. Fire scenarios include amount and organization of flammable substances, disposition and character of object, design of fire safety systems, fire origin area, position and other parameters which influence resultant values describing fire. These data differ a little according to particular purpose of the model. Despite, it is possible to create a basic division of input parameters into several groups relating to fire load, gas exchange with environment and the space (room) description, in which the fire takes place.

Deterministic models are divided into two independent subsets: zone models and field models (based on computer technology CFD, see Fig. 8).

The most important feature of computational fire models is their ability to realistically predict the process of design fire within the range of their set parameters. The main disadvantage of these fire models in engineering practice are, however, relatively high set input parameters requirements and the time needed for the evaluation (especially by field models).

\section{Conclusion}

Building constructions fire resistance assessing using methods according to Eurocodes or using engineering principles is without 

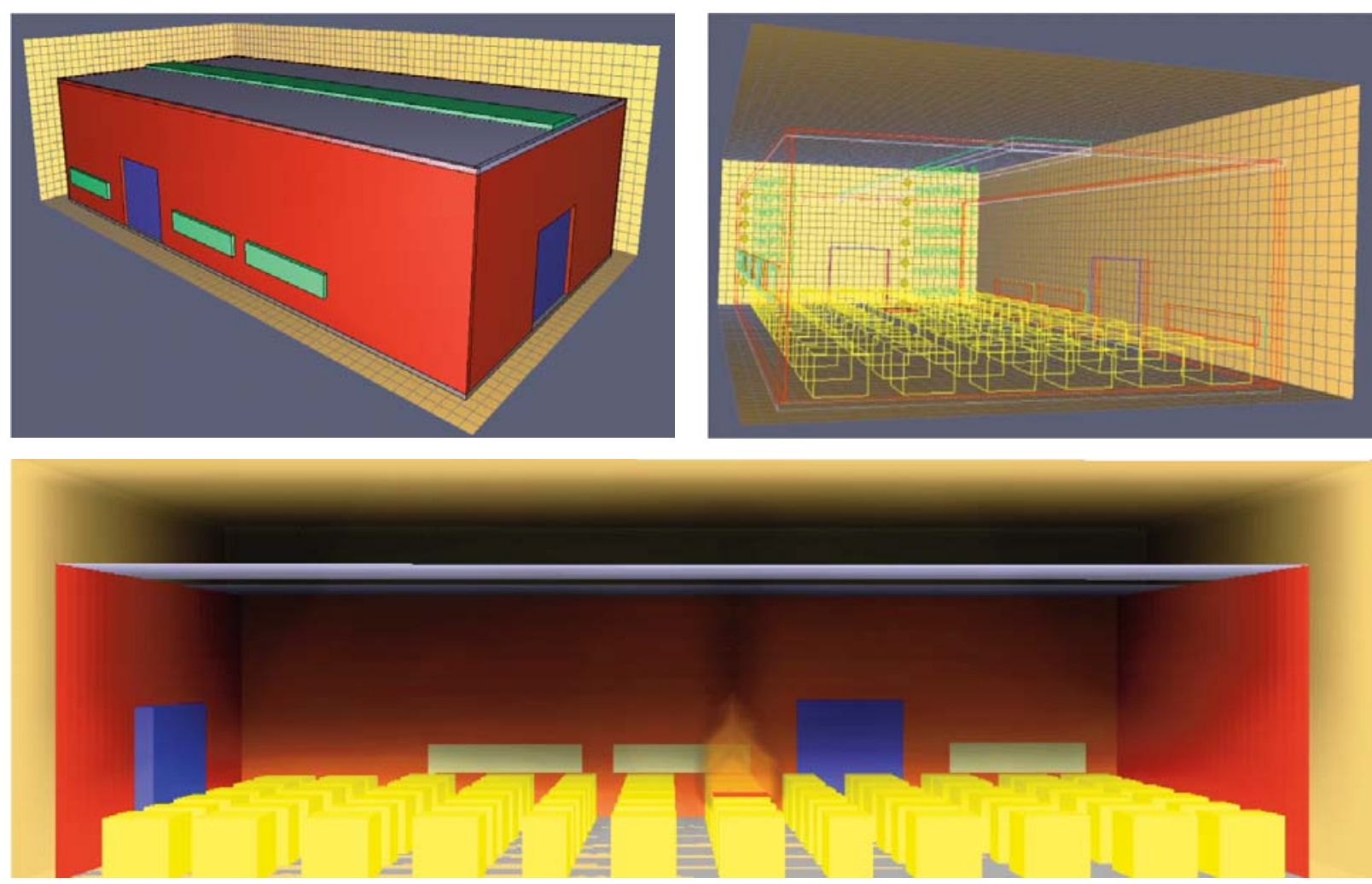

Fig. 8 Example of fire field model visualization (CFD model)

doubt a sunrise area which will also in future find constantly wider use.

Also through variety of procedures for thermal analysis of area, where fire development take place, and building construction, it is obvious that many of them (for example localised fire methods, parametric fire curves), have their significant limitation. It is necessary to respect the limits of evaluative methods by assessing building constructions fire resistance.

\section{References}

[1] CSN EN 1991-1-2 Eurocode 1: Actions on Structures - Part 1-2: General actions - Actions on Structures Exposed to Fire, Praha : UNMZ, 2004, p. 56.

[2] CSN 730804 Fire Protection of Buildings - Industrial Buildings, Praha : UNMZ, 2010, p. 156.

[3] CSN 730810 Fire Protection of Buildings - General Requirements, Praha: UNMZ, 2009, p. 44.

[4] HESKESTAD, G.: Fire Plumes, Flame Height, and Air Entrainment, SFPE Handbook of Fire Protection Engineering. Fourth Edition, Section 2, Chapter 2-1. Quincy: National Fire Protection Association, 2008, p. 1-20, ISBN-10: 0-87765-821-8, ISBN-13: 978-0-87765-821-4.

[5] POKORNY, J.: Fundamental of Thermal Analysis of Smoke Plume, In: Sbornik prednasek XVIII. mezinarodni konference Pozarni ochrana 2009, Ostrava: VSB-TUO, FBI, SPBI a HZS MSK, 2009. pp. 457-467, ISBN 978-80-7385-067-8.

[6] POKORNY, J.: Assessment of Axial Temperature of Smoke Plume with Regard to Hot Gases Layer, SPEKTRUM, Vol. 10, No. 1, Ostrava: Sdruzeni pozarniho a bezpecnostniho inzenyrstvi, 2010, pp. 21-24, ISSN: 1211-6920 (print), 804-1639 (on-line).

[7] KUCERA, P., KAISER, R., PAVLIK, T., POKORNY, J.: Fire Engineering - Fire Dynamics (in Czech), EDICE SPBI SPEKTRUM 65, Ostrava : Sdruzeni pozarniho a bezpecnostniho inzenyrstvi, 2009, p. 152, ISBN 978-80-7385-074-6.

[8] KUCERA, P., KAISER, R., PAVLIK, T., POKORNY, J.: Methodical Approach in Different Way of Satisfy Technical Conditions of Fire Protection (in Czech), EDICE SPBI SPEKTRUM 56. Ostrava : Sdruzeni pozarniho a bezpecnostniho inzenyrstvi, 2008, p. 201, ISBN 978-80-7385-044-9.

[9] KUCERA, P., KAISER, R.: Introduction to Fire Engineering (in Czech), EDICE SPBI SPEKTRUM, sv. 52, Ostrava : Sdruzeni pozarniho a bezpecnostniho inzenyrstvi, 2007, p. 170, ISBN 978-80-7385-024-1.

[10] ISO/TS 16733 Fire Safety Engineering - Selection of Design Fire Scenarios and Design Fires. Geneva, ISO, 2006. 